\title{
Keeping TOCE on a Positive Trajectory
}

\author{
CHRISTOPHER D. HUNDHAUSEN, Washington State University
}

\begin{abstract}
In my inaugural editorial as the new editor-in-chief of the ACM Transactions on Computing Education, I take stock of the journal's progress in its first 6 years of existence, and I describe my plans to help the journal maintain its positive trajectory as a viable and vibrant computing education research journal.
\end{abstract}

\section{CCS Concepts: $\bullet$ Social and professional topics $\rightarrow$ Computing education}

Additional Key Words and Phrases: Computing education research

\section{ACM Reference Format:}

Christopher D. Hundhausen. 2016. Keeping TOCE on a positive trajectory. ACM Trans. Comput. Educ. 16, 1, Article 1e (February 2016), 3 pages.

DOI: http://dx.doi.org/10.1145/2872275

I have been a big fan of the ACM Transactions on Computing Education (TOCE) ever since founding co-editors-in-chief Josh Tenenberg and Robert McCartney made the journal a reality in 2009. I think that TOCE addresses an important need in the ACM community, namely, the need for a reputable journal in which to publish high-quality articles on computing education research at the primary, secondary, and postsecondary levels. Such research addresses not only theories and methods but also effective pedagogical approaches, learning processes, and supporting technologies. In the 6 years since the journal was founded, I have watched the journal gain a solid reputation as a leading publication venue for computing education research.

I am excited to take over as the TOCE's new editor-in-chief, and I have some ideas for how to help the journal continue on its positive trajectory. Before I share them, however, I would first like to consider where TOCE stands at this moment in its history. In their final editorial, outgoing editors-in-chief Josh Tenenberg and Robert McCartney [2015] aptly describe two key constraints faced by TOCE in its early years: the rationality constraint and the viability constraint. The rationality constraint relates to the need to define criteria for evaluating submissions to the journal that are not only consistent and coherent but also acceptable to the community of computing educators and researchers served by TOCE. The viability constraint has to do with the need to maintain viability as a journal. This entails the need both to attract a sufficient number of acceptable articles and to capture the attention of a sufficiently large readership.

As Tenenberg and McCartney note, the fact that computing education research is in its infancy as a discipline has made navigating these constraints particularly challenging. However, through a conscientious and reflective process that has involved dialectical interactions among authors, TOCE associate editors, TOCE guest editors,

Author's address: C.D. Hundhausen, Human-centered Environments for Learning and Programming (HELP) Lab, School of Electrical Engineering and Computer Science, Washington State University, Pullman, WA 99164-2752; email: hundhaus@wsu.edu.

Permission to make digital or hard copies of part or all of this work for personal or classroom use is granted without fee provided that copies are not made or distributed for profit or commercial advantage and that copies show this notice on the first page or initial screen of a display along with the full citation. Copyrights for components of this work owned by others than ACM must be honored. Abstracting with credit is permitted. To copy otherwise, to republish, to post on servers, to redistribute to lists, or to use any component of this work in other works requires prior specific permission and/or a fee. Permissions may be requested from Publications Dept., ACM, Inc., 2 Penn Plaza, Suite 701, New York, NY 10121-0701 USA, fax +1 (212) 869-0481, or permissions@acm.org.

(c) 2016 ACM 1946-6226/2016/02-ART1e $\$ 15.00$

DOI: http://dx.doi.org/10.1145/2872275 
and the editors-in-chief, TOCE has done a laudable job of addressing these constraints. It now has a review process in place that attracts initial paper submissions that are much closer to meeting the threshold for publication than was initially the case. Moreover, TOCE consistently meets the ACM's annual page allocation quota (480 pages per year), and TOCE ranks seventh among 39 comparable ACM journals and transactions with respect to the extent to which its articles are downloaded [Tenenberg and McCartney 2015]. Thus, it appears that the enterprise I am taking over as editor-inchief is on a positive trajectory.

How do I plan to help TOCE stay on this positive trajectory? When I took over the editor-in-chief position in September of 2015, my first job was to select a new editorial board. In the interest of maintaining TOCE's stature as a leading computing education research journal, I stacked the new editorial board with leading researchers in the field. The new editorial board, whose 21 members are listed at http://toce.acm.org/editorial.cfm, includes not only many seasoned veterans from the previous editorial board but also some younger researchers who have already made a mark on the field. My goal in forming the new editorial board was to balance the need for expertise across a variety of computing education research topics with the need for outstanding researchers and educators who can provide authors with insightful feedback and help them connect their work to relevant literature in the field. I feel I have succeeded in both regards, and I am excited to work with the members of the editorial board in the years ahead.

In addition, in response to feedback from TOCE reviewers and members of the editorial board (and here, I would especially like to single out editorial board member Beth Simon for her help), I have already taken on a second important initiative in my role as editor-in-chief: that of redesigning $T O C E$ 's review form, which some felt could benefit from an overhaul. To that end, I posted the current review form online, and had the editorial board comment on the form's structure and questions. In a followup phone conference in which more than half of the editorial board participated, we hashed out the design of an improved review form.

I believe that the new review form, which will go live in early 2016 , will enable reviewers to furnish more helpful and constructive reviews relative to TOCE's review criteria. More structured than the previous review form, the new review form contains three main sections: (a) situate the article, (b) assesses the article's impact, significance, and scholarship; and (c) provide a recommendation and rationale. In the first two sections, a series of questions ask reviewers to assess the article relative to key aspects of the review criteria so that reviewers can zero in on those aspects of the article that are most relevant. In the third section, the review form prompts reviewers to provide a recommendation for the article and to back up that recommendation by identifying the article's contributions, strengths, and weaknesses. Finally, reviewers are prompted to provide constructive feedback on how the article can be improved. While I am confident that this new review form will lead to better reviews, I recognize that improvements generally come about through an iterative process of refinement. I, therefore, expect to revisit various aspects of TOCE's review form and process in the future.

In the upcoming year, I have additional plans to help keep TOCE on a positive trajectory. First, I have set new targets for each phase of the review process in an effort to reduce, to just 10 weeks, the average time an article is in review. (At present, it takes 3 to 6 months for an article to be reviewed and a decision to be forwarded to the article's authors.) Second, I would like to increase the visibility of ACM TOCE articles by helping to establish a special track for TOCE articles at the ACM SIGCSE Symposia. This approach, which has been successfully adopted by other ACM journals such as ACM TOCHI, will further incentivize submissions by giving TOCE authors the opportunity to present their work to a large audience of computing education 
researchers and practitioners at a premier computing education conference. Third, although it will require special permission, I, along with the majority of the editorial board, would like to change TOCE's review process to be double-blind. There is a precedent for this in top research journals, and even at other ACM computing education conferences (ACM ICER and SIGCSE). In the coming year, I will explore this possibility further. Fourth, I will aggressively recruit guest editors for special issues of broad interest to computing educators and researchers. A special issue on learning analytics for computing education is presently in the works; I would welcome further suggestions from the TOCE community.

I will close by asking you a question: How would you like to see TOCE continue on a positive trajectory? After all, as a journal reader, contributor, and member of the computing education community, this is your journal. I stand ready to listen to your ideas and suggestions, so that, together, we can help ACM TOCE maintain its positive trajectory as a leading computing education research journal.

\section{REFERENCE}

Josh Tenenberg and Robert McCartney. 2015. Looking backward to look forward: TOCE in transition. Trans. Comput. Educ. 15, 3 (Sept. 2015), Article 12, 8 pages. DOI : http://dx.doi.org/10.1145/2817209

Received December 2015; revised February 2016; accepted February 2016 